\title{
A INDIFRENÇA DA HUMANIDADE PARA COM OS REFUGIADOS DA TERRA: UMA PROBLEMÁTICA ÉTICO-POLÍTICA DA ATUALIDADE
}

\author{
HUMANITY INDIFFERENCE FOR EARTH REFUGEES: A CURRENT \\ ETHICAL-POLITICAL PROBLEM
}

\author{
Valdir Borges ${ }^{1}$ \\ Luiz Alberto de Alcantara ${ }^{2}$ \\ Gabriela Ribeiro Campos ${ }^{3}$
}

\section{RESUMO}

Nossa proposta é analisar e refletir a indiferença da humanidade para com os refugiados da terra: uma problemática ético-política da atualidade. Neste ano de 2018, a obra Pedagogia do oprimido, de Paulo Freire completa 50 anos, porém, se encontra vigente, no que tange à sua denúncia referida à opressão no contexto histórico-social da América Latina dos anos 1960 e 1970. Em seguida, analisaremos a indiferença desde a ótica da ética e da política, como marca indelével da problemática em voga: os refugiados da terra nos dias hodiernos são os oprimidos, colonizados e condenados da terra de ontem. Apontamos pistas e vias de libertação para a crise migratória, que no fundo é uma crise humanitária, desde as perspectivas da ética, da economia e da política com Zygmunt Bauman e Adela Cortina Orts.

Palavras chave: Paulo Freire; Indiferença; Crise migratória.

\section{ABSTRACT}

Our proposal is to analyze and reflect the indifference of humanity towards the refugees of the earth: an ethical-political problematic of the present time. In this year of 2018, Paulo Freire's work "Pedagogy of the Oppressed" completes its 50th anniversary, but it is still in force with regard to its denunciation of oppression in the historical-social context of Latin America in the 1960s and 1970s. We will analyze the indifference from the point of view of ethics and politics as an indelible mark of the problematic in vogue: Daterran refugees today are the oppressed, colonized and condemned from

\footnotetext{
${ }^{1}$ Doutor em Educação, Mestre em Filosofia e Professor de Filosofia e Educação da Pontifícia Universidade Católica do Paraná - PUCPR. valdirb@hotmail.com

2 Doutorando em Educação, Mestre em Educação pela Pontifícia Universidade Católica do Paraná - PUCPR. luizalbertodealcantara@gmail.com

${ }^{3}$ Doutoranda em Educação, Mestra em Educação pela Pontifícia Universidade Católica do Paraná - PUCPR. Gabriela.campos3@gmail.com
} 
the land of yesterday. We point out ways and means of liberation for migration, which is fundamentally a humanitarian crisis, from the perspectives of ethics, economics and politics with Zygmunt Bauman and Adela Cortina Orts.

Keywords: Paulo Freire. Indifference. Migratory crisis.

\section{INTRODUÇÃO}

Neste ano de 2018, o supracitado livro do pernambucano Paulo Freire Pedagogia do Oprimido comemora o jubileu de ouro. Publicado em 1968, durante o exílio no Chile, essa obra teve e ainda tem grande impacto nos quatro quanto do planeta. Paulo Freire apresentanos a dialética relação entre opressores e oprimidos, no contexto latino-americano. Desta controversa relação, Paulo Freire denuncia a opressão vivenciada pelos silenciados, "os condenados da terra", os "colonizados", "os esfarrapados e aos que neles se descobrem e, assim descobrindo-se, com eles sofrem, mas, sobretudo, com eles lutam”. (FREIRE, 2005, p. 23).

Paulo Freire propõe uma pedagogia crítica, uma revolução pedagógica libertadora. Uma pedagogia que não é "para" o oprimido, mas "do" oprimido. Nesta perspectiva, propusemos verificar o contexto em que Pedagogia do Oprimido foi inserida, analisar que a indiferença para com o refugiado da terra tornou-se uma problemática ético-política, e propor uma conscientização necessária para voltarmos nossa atenção para a crise migratória, na qual milhares de "estranhos batem à nossa porta", a procura de ajuda, buscando dignidade humana. A crise migratória, não assombra somente o continente europeu, mas, é um problema global, que atinge todo planeta. Acreditamos que a responsabilidade ético-política pode proporcionar e conduzir nossas atitudes diante da problemática que está anunciada.

\section{METODOLOGIA}

Para realização da pesquisa optou-se por realizar uma pesquisa documental e bibliográfica, que por meio de uma análise de conteúdo de documentos selecionados, estabeleceu-se um diálogo crítico com as fontes.

Os dados foram problematizados com apoio das obras de Barbu (1962), Bauman (2017), Borges (2013), Cortina Orts (2017), Fanon (1968), Freire (1974, 2003, 2005, 2011), 
Memmi (1967) entre outros, buscando verificar, analisar, agir e dialogar com a interface da indiferença da humanidade para com os refugiados da terra: uma problemática ético-política da atualidade.

\subsection{Pedagogia do Oprimido: origem, contexto histórico-social e vigência}

Após 50 anos de sua primeira publicação, o livro Pedagogia do Oprimido de Paulo Freire "permanece vigente, dada as suas constantes re-edições no Brasil e no exterior, e aos novos tipos de oprimidos que surgem a cada dia em nossa sociedade" (BORGES, 2008, p. 211).

Continua-se a difundir uma obra que nos faz olhar para a indiferença da humanidade, para com os excluídos e nos leva a uma postura radical frente a esse problema ético-político. $\mathrm{Na}$ Introdução da referida obra, Freire a dedica "aos esfarrapados do mundo e aos que neles se descobrem e, assim descobrindo-se, com eles sofrem, mas, sobretudo, com eles lutam" (FREIRE, 2005, p. 23), pode ser dedicada hoje aos novos tipos de oprimidos que surgem a cada dia em nossa sociedade; especialmente, no que tange aos refugiados da terra, por todo tipo de exclusão social, política, ética e econômica.

Em Pedagogia do Oprimido, a obra prima de Freire expõe que o educador traz à tona a questão da relação dialética entre opressores e oprimidos, de como se necessita uma práxis que possa orientar uma ação visando à superação dessas contradições. Essa obra "pintada" por Paulo Freire propõe uma pedagogia abrangente, pela qual a palavra e o processo de conscientização ajudam o ser humano a tornar-se o sujeito de todo o processo histórico.

O livro continua popular e vigente entre educadores no mundo inteiro, considerado um dos fundamentos da pedagogia crítica e da educação libertadora. Entendemos que a relação opressores e oprimidos, denunciada por Paulo Freire, em 1968, continua vigente no contexto histórico-social hodierno; mas, em forma de outros opressores e outros oprimidos, em que a mídia não busca ou apresenta soluções, mas apresenta-se com indiferença. Sendo assim, evidenciamos a insensível indiferença como uma problemática ético-política da atualidade.

\subsection{A indiferença como uma problemática ético-político da atualidade}




\section{novistet

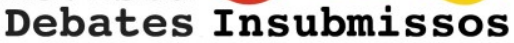

A indiferença com o outro nos apresenta um desafio, que também compreendemos como uma problemática ética e política da atualidade global. Entendemos que a questão éticopolítica pode e deve apresentar respostas para esta implicação que não é local e regional, mas, se nos apresenta na perspectiva global. A indiferença ética está relacionada com nosso comportamento individualista, conforme registra Nadja Hermann:

[...] o que não se articula pela razão tende a ser desvalorizado e até excluído. Tratase de um individualismo exacerbado, possessivo, uma atomização do mundo, em que a luta de cada um pela autopreservação determina aquilo que se interpõe a tal processo como barreira e como estranho (HERMANN, 2014, p. 482).

A indiferença pode ser ética e política, os conflitos que evidenciamos em nossa sociedade atual ultrapassam as fronteiras, chegam a patamares da esfera global, que necessitam de mudança de comportamento, partindo do individual para que possamos chegar ao coletivo. Nesta perspectiva, passaremos a resgatar a partir dos problemas enfrentados no Brasil, para que possamos dimensionar na escala global. Desta forma,

O Brasil, país conhecido internacionalmente pelas abismais desigualdades nos diversos âmbitos da vida, ecoa sempre mais o clamor e a sede de justiça e equidade social onde se travam duros embates pela justa medida na distribuição de oportunidades e recursos, ainda concentrados nas mãos de uma casta privilegiada. Esse processo de injustiça e indiferença social é o resultado desastroso da selvageria do atual capitalismo globalizante, pautado no lucro e na economia de mercado. Neste, há um processo de separação entre os que detêm as condições e oportunidades e aqueles que são excluídos, parcial ou totalmente, de qualquer participação social, política, cultural ou econômica. (BORGES \& ALCANTARA, 2018, p. 1).

Esta indiferença social, partindo do contexto brasileiro, é um retrato latino-americano, que, assim como no Brasil, viveu a colonização, a opressão e a vulnerabilidade de seus povos. Esta opressão manifestada na colonização latino-americana está evidenciada no contexto hodierno. A tentativa de negar o outro, não é apenas uma desvalorização, mas uma ameaça à tentativa de aprender a conviver democraticamente.

Uma sociedade democrática pode possibilitar a participação de todos na construção do inédito viável ${ }^{4}$. Vivemos em uma sociedade democrática, mas ainda precisamos de uma reforma, assim como evoca o romeno Zevedei Barbu: "uma reforma democrática ou uma ação

\footnotetext{
${ }^{4}$ Expressão utilizada por Freire em "Pedagogia da Esperança" e explicada em nota por Ana Maria Araújo Freire. Em outro livro, fruto de um seminário da Secretaria Municipal de Educação de Porto Alegre, "Utopia e Democracia na Educação Cidadã", 2000, José Clóvis de Azevedo, Pablo Gentili et al (orgs), Ed. Da Universidade/UFRGS, Ana Maria Freire resgata esse termo num texto de sua autoria.
} 
democrática geral, deve ser levada a efeito, não apenas com o consentimento do povo, mas também, com a sua intervenção" (BARBU, 1962, p.20).

Para Zevedei Barbu mais que um conceito político, a democracia é uma forma de vida, e a essência daquilo que compreendemos por democracia está no fato dela representar um modo ético de vida. A democracia traz em si uma base racional da modalidade, sem isso não há soberania do povo, mas apenas discurso democrático. Paulo Freire, em Educação como Prática da Liberdade, conhece e aprofunda a concepção de democracia que expusemos a de Zevedei Barbu e sustenta que a democracia que, antes de ser forma política, é forma de vida, se caracteriza, sobretudo por forte dose de transitividade de consciência no comportamento do homem. Transitividade que não nasce e nem se desenvolve a não ser dentro de certas condições em que o homem seja lançado ao debate, ao exame de seus problemas e dos problemas comuns. Em que o homem participe. (FREIRE, 2007, p. 88).

O que evidenciamos e vivemos no contexto hodierno é uma indiferença geral, que trataremos aqui, como problema ético-político. Entendemos que a diferença revela uma condição do ser humano, já a indiferença é uma marca que não reconhece a responsabilidade com o outro e com o mundo. Desta forma, analisamos a indiferença com o outro e com o mundo como indício paradoxal mais visível do que com a formação humana.

O processo que nos torna humanos envolve a aceitação da nossa corporeidade, a interação e o estímulo às forças criativas próprias. Ou seja, compreende a imprescindível presença do outro na busca por reconhecimento, o que nos aproxima e, ao mesmo tempo, inquieta e projetamos à ação, mostrando inclusive os limites de nossa visão de mundo, como revela Maria do Céu Neves: "uma inquietude perante um agir que ora fica aquém do pensar, ora se precipita em ultrapassar, e sempre, em qualquer dos casos, constituindo o seu ser, cinzelando a sua identidade" (NEVES, 2017, p 11).

Esta inquietude de pensar, refletir, duvidar, questionar, decidir e também de agir, é uma implicação ético-política. A educação possibilita a compreensão, reflexão e liberdade necessárias para tomada de decisão diante dos desafios enfrentados. Para Paulo Freire (1974, p. 26), a Educação para liberdade implica o exercício perene da consciência voltado para si mesmo com vistas a descobrir-se a si próprio nas suas relações no e com o mundo. Paulo 
Freire expõe a arqueologia da consciência, numa entrevista à Revista inglesa Risk ${ }^{5}$, conforme segue:

[...] consciência é intencionalidade voltada em direção ao mundo. Quando eu deste modo, penso numa "arqueologia da consciência", estou a pensar que através da problematização das relações entre os homens e o mundo, é possível ao homem recriar, refazer, o processo natural através do qual surgiu a consciência no processo de sua evolução, precisamente naquele momento a que Teilhard de Chardin chama "hominização" na evolução do homem. (FREIRE, 1974, p. 25).

Paulo Freire evidencia a importância das relações dos condenados da terra, dos silenciados, negados e oprimidos com o mundo e de sua consciência com o mundo, pois não existe dicotomia entre a consciência e o mundo. Aspectos esses presentes nas obras de Paulo Freire, pertencentes a sua influência existencialista. Por isso, a conscientização para Paulo Freire: “implica uma reflexão crítica sobre o mundo tal como ele devém e ao anunciar outro mundo, não pode fazer abstração duma ação de transformação de modo a permitir que esta predição se concretize". (FREIRE, 1974, p. 57).

A consciência necessária para viver eticamente é renunciar a atitude de dominação dos outros para estar junto e viver de forma responsável e solidária como base ao entendimento rico em possibilidades de relações materializadas na linguagem. É com essa perspectiva de abertura dos sujeitos ao mundo da vida, permeada por saber, cultura, linguagem, história, formação, que surge a relação integradora e vivificante do movimento, capaz de produzir a sensibilidade diante da presença do outro. Esse outro tem rosto e necessita ser liberto de toda forma de exclusão, de opressão com vistas à libertação integral.

\section{OPRESSÃO E LIBERTAÇÃO DOS REFUGIADOS DA TERRA NA CONTEMPORANEIDADE: ONTEM E HOJE}

Após mostrarmos a vigência e a atualidade da obra prima freireana, Pedagogia do Pprimido, 50 anos depois e expormos a indiferença como um problema ético-político,

\footnotetext{
${ }^{5}$ Entrevista realizada pela revista de língua inglesa RISK, World Council for Christian Education, Genebra, em 15 de novembro de 1970, tendo sido inserida no ${ }^{\circ} 4$, desse mesmo ano. (FREIRE, 1974, p. 23-40).
} 
elucidaremos a opressão vivenciadas por alguns importantes autores, cujas obras expressam a dor da opressão e apontam caminhos para a libertação.

Iniciaremos com algumas reflexões a partir dos escritos de Albert Memmi, Frantz Fanon dos anos 1950 e 1960, para terminar com as reflexões da atualidade que retratam a indiferença, no início deste terceiro milênio e século XXI, como um problema ético, social, político e até cultural, para com os refugiados da terra, nos Estranhos à Nossa Porta, de Zygmunt Bauman; e na Aporofobia ,de Adela Cortina Orts.

Iniciaremos pela denúncia de Albert Memmi, realizada em sua obra, escrita em 1957, Retrato do colonizado precedido pelo retrato do colonizador. Sua obra desponta em um contexto histórico-social de descolonização da África; especialmente, dos movimentos de libertação surgidos na Argélia e na Tunísia, em que ele aponta os olhos do colonizador em relação ao colonizado, denunciando as tiranias, pobreza e corrupção, vigentes em países da África, mostrando o drama da colonização e opressão, feridas de humilhação, perpetradas pelo centro hegemônico europeu, especialmente a França.

Esse retrato dramático 'pintado' por Albert Memmi, no contexto anterior à guerra franco-argelina, de 1961-1962, na obra supracitada, se refere à realidade opressora, em qualquer parte do mundo, seja na África, na Ásia, América Latina (BORGES, 2013, p. 153), e nos dias hodiernos, sobretudo, na Europa, onde existe uma verdadeira tormenta social, de discurso e ações de ódio contra os refugiados da terra, seja, pela fome, ou pelas guerras.

E, Albert Memmi chama a atenção para a 'consciência colonizada', que imprime o mito da inferioridade no colonizado, destacando que há duas respostas do colonizado em relação ao colonizador, que poderá ser de amor ao colonizador, bem como de ódio e revolta a si mesmo, introjetadas na consciência do colonizado (BORGES, 2013, p 152). Sobre isso, é importante salientar o que expressa Albert Memmi: “[...] a primeira ambição do colonizado será a de igualar-se a esse modelo prestigioso, de parecer com ele até nele desaparecer" (MEMMI, 1967, p. 107).

Este clássico retrato do colonizado, 'pintado' por Albert Memmi é inspirador à obra prima freireana, Pedagogia do Oprimido (FREIRE, 2005), para dar respostas e retratar ao oprimido latino-americano dos anos 1960 e 1970, outro clássico, que continuará vigente, enquanto houver um oprimido, esfarrapado, condenado, ou refugiado da terra. 
Além dessas inspirações, Paulo Freire conhece a Frantz Fanon, os condenados da terra e o cita (FREIRE, 2005, p. 34-35; 55), escrita em 1961, acerca dos efeitos devastadores da colonização e do processo de descolonização africana. Esse se constitui como uma das pedras angulares da luta anticolonial e da possibilidade de uma nova sociedade, que apesar da consciência humilhada contemporânea, inspira o anseio de um mundo melhor, mais igual e com menos indiferença.

Na denúncia de Fanon não cabe a conciliação entre o colonizado e o colonizador, pois o colono é sempre visto como inimigo, inclusive atesta situações limites como os transtornos mentais, afetivo-intelectuais, fruto das condições subumanas e vexatórias da tortura, a que os norte- africanos eram submetidos (FANON, 1968, p. 209-267). Para compreender os diversos entrelaçamentos entre Paulo Freire, Albert Memmi e Frantz Fanon contra todo tipo de opressão, em qualquer tempo e lugar da terra com vistas à libertação, remetemos à obra: $a$ reconstrução de uma ética pedagógica libertadora à luz de Paulo Freire (BORGES, 2013, p.152-156).

Inspirados nestas linhas do ontem da contemporaneidade, faz-se míster, adentrarmos aos dias hodiernos no que tange à disseminação, à aversão, ao ódio aos novos condenados da terra, novos colonizados, novos oprimidos, ontem denunciados por Frantz Fanon, Albert Memmi e Paulo Freire, supra descritos e que clamam por libertação.

Nos dias hodiernos, seguiremos duas obras de alcance mundial acerca da problemática ética e sociopolítica da atualidade, no que tange aos refugiados da terra, através do sociólogo polonês Zygmunt Bauman com Estranhos à nossa porta e da espanhola, catedrática em ética, Adela Cortina Orts. Ambas as obras, recentes, de 2017, 'pintam', retratam os oprimidos hodiernos, os refugiados da terra, como uma problemática ética e política, primada pela indiferença, de uma humanidade que finge não ver o que se passa à sua volta. Essa indiferença se faz 'carne' nos esfarrapados, maltrapilhos, condenados, refugiados da terra, que são colocados em situações subumanas, vexatórias, tratados como a escória humana ou o lixo da humanidade, aqueles que o sistema econômico do mercado globalizado os descartou, ou ainda não os assimilou.

Zygmunt Bauman denuncia a hipocrisia da mídia na forma de como aborta a atual 'crise migratória', que atinge diversas partes do mundo; especialmente, a Europa, pondo em 
crise a própria União Europeia. A mídia não busca ou aponta soluções, mas provoca comoção em relação aos refugiados da terra, promovendo a insegurança existencial, ideologicamente, acerca dos refugiados da terra, tal é o impacto das notícias, "que chega a causar um verdadeiro 'pânico moral', que ameaça o bem-estar da sociedade idealizada pelo liberalismo" (BAUMAN, 2017, p 7-8).

Essa 'insegurança' é aquilo pelo que se valem as instituições sociais que, em proveito próprio, empossam governos que combatam o terrorismo e junto deles entram nesta categoria os demais refugiados da terra. Dessa forma, a sociedade se isenta de suas responsabilidades sociais, políticas e éticas acerca do destino dos miseráveis, dos refugiados da terra, criando “uma política de 'securitização', que ajuda a reprimir, antecipadamente, nossas dores de consciência” (BAUMAN, 2017, p.38). Ele ainda destaca que o fenômeno migratório é antigo e possui diversas causas (BAUMAN, 2017, p. 13) e que na modernidade, a indiferença é tal que: “a presença de 'remanescentes' é um fenômeno global, que não se restringe à Europa”.

“Este termo, 'remanescentes' se refere a pessoas afastadas da vista, das preocupações e da consciência" (BAUMAN, 2017, p. 89). Remanescentes são aqueles que a sociedade moderna excludente os considera inútil. Esses são os atuais refugiados da terra, que sobram, são os novos oprimidos de Paulo Freire, os novos colonizados de Albert Memmi e os novos condenados da terra de Frantz Fanon, excluídos da participação da economia de mercado, descartados como a sobra, afastados da vida e da cidadania, alijados da participação nas decisões políticas, marginalizados pela indiferença, que se tornou um dos maiores problemas éticos dos tempos hodiernos.

Essa insensível indiferença ética e política são provocadas pela cegueira moral de uma humanidade em crise, que está chegando a um ponto de 'fadiga da tragédia dos refugiados' (BAUMAN, 2017, p. 8). As raízes do ódio em relação aos conflitos que envolvem os refugiados da terra representam para a humanidade uma verdadeira ameaça, que além de expor as misérias humanas, mostram as mazelas que causam o 'pânico moral' em relação ao fluxo migratório, mais que uma crise migratória é uma crise humanitária.

Esse problema não se enfrenta, nem com políticos tiranos, governos infames ou a sociedade em geral e sobre a trilha dos tiranos; "um espectro está assombrando as terras da democracia: o espectro dos opressores" (BAUMAN, 2017, p. 49). Mas além da indiferença 


\section{novistet

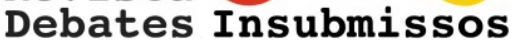

social, política e ética que geram a opressão, Zygmunt Bauman aponta pistas para a libertação em relação aos refugiados da terra: "a humanidade está em crise - e não existe outra saída para ela senão a solidariedade dos seres humanos" (BAUMAN, 2017, p.24).

$\mathrm{Na}$ esteira de Zygmunt Bauman, temos uma pensadora, filósofa, catedrática de Ética e Filosofia Política da Universidade de Valência, Adela Cortina Orts que com seu talento nos conduz à reflexão profunda do acontecimento contemporâneo, em especial, relacionados à aversão, fobia, ódio aos pobres, designado por ela de aporofobia, especialmente, os estrangeiros pobres, aos refugiados da terra, na sua mais recente obra Aporofobia, el rechazo al pobre un desafio para la democracia, publicada em 2017. Ela provoca uma sacudida no discurso moral e ético vigente, expondo a questão dos imigrantes refugiados na Europa, para nós todos os refugiados da terra, como um problema ético e da necessidade urgente de entender a esfera política, como a ferramenta do bem comum, para enfrentarmos com responsabilidade social esta problemática candente.

A crise dos refugiados e dos imigrantes, especialmente na Europa, está colocando em questão a própria concepção de União Europeia, pois desprezar e negar a hospitalidade aos pobres está abaixo de um mínimo de justiça e de ética esperados. Muito mais do que xenofobia, aversão aos estrangeiros, existe na atualidade uma aversão, ódio, fobia, desprezo ao estrangeiro pobre, que está subentendido, no recente neologismo, cunhado por Adela Cortina, aporofobia.Vejamos o que ela conclui a esse respeito:

El problema no es entonces de raza, de etnia ni tampoco de extranjería. El problema es de pobreza. Y lo más sensible en este caso es que hay muchos racistas y xenófobos, pero aporófobos, casi todos. Es el pobre, el áporos, el que molesta, incluso el de la propia familia, porque se vive al pariente pobre como una vergüenza que no conviene airear, mientras que es un placer presumir del pariente triunfador, bien situado en el mundo académico, político, artístico o en el de los negocios. Es la fobia hacia el pobre la que lleva a rechazar a las personas, a las razas y a aquellas etnias que habitualmente no tienen recursos $y$, por lo tanto, no pueden ofrecer nada, o parece que no pueden hacerlo.(CORTINA, 2017, p.21).

Na mesma ótica de Zygmunt Bauman, Adela Cortina Ortz, na obra supracitada, aponta vias de reais de libertação dessa realidade, por ela designada, também, como tormenta social. Somente uma economia ética empenhada em investir na educação e nas pessoas, na melhoria de vida, na redução das desigualdades, em que juntas, a iniciativa privada e pública, conscientes da sua responsabilidade e justiça social poderão fazer frente a crise migratória, 
que antes de tudo, é uma crise humanitária. Dessa forma, se derrubaria os muros da indiferença para construirmos juntos, as pontes de uma nova Europa social, ou em qualquer lugar social em que haja um refugiado da terra.

\section{CONCLUSÃO}

À guisa de conclusão, este artigo, inserido na sétima temática, que tange à ética e política do X Colóquio Internacional Paulo Freire: 50 anos de Pedagogia do oprimido, buscou analisar a indiferença da humanidade para com os refugiados da terra, na perspectiva ética e política. Um dos maiores problemas que assola a humanidade na atualidade, a recente crise migratória, especialmente a européia, que na realidade, é uma crise humanitária.

Ao revisitar Paulo Freire, Frantz Fanon e Albert Memmi, foi possível perceber que os oprimidos, os condenados da terra, os colonizados da contemporaneidade de ontem, são os imigrantes, os refugiados da terra hodiernos, sejam eles, europeus, asiáticos, africanos, latino-americanos, ou de qualquer lugar da terra, nossa casa comum.

A marca característica e indelével de ontem e de hoje é a indiferença da humanidade, tratada aqui como um problema ético e político, pois nos isenta da responsabilidade, hospitalidade e da justiça social, conduzindo-nos à perversão, que é a opressão, a aversão, a rejeição ao outro, que tem rosto e clama por solidariedade e justiça. A ética tange ao comportamento de individualismo, indiferença, estranheza e distância dos demais. E desde a ótica política, quando não se almeja o bem comum e a cidadania. A indiferença machuca, fere e afasta da vida o refugiado da terra, sem a mínima hospitalidade e justiça social.

A aversão e o ódio, fruto da insensível indiferença e disseminados contra os refugiados da terra, especialmente, na Europa, é a maior problemática ética e política da humanidade hodierna denunciada, aqui, por Bauman e Cortela, por nós analisados e referenciados. Ambos apontam pistas e vias de libertação pelo viés da ética, da política e da economia.

A saída, o remédio, ao nosso modo de ver, seguidos por esses dois autores, é a solidariedade dos seres humanos que evoca a responsabilidade social e a justiça, diminuindo, grandemente, os obstáculos da insensível indiferença. Há uma necessidade, urgente, de uma economia ética, empenhada na educação e nas pessoas para melhorar as condições de vida e a 
redução das desigualdades.Tudo isso prova a vigência de Pedagogia do oprimido, 50 anos depois, e os postulados e pressupostos freireanos ali contidos, pois os esfarrapados do mundo, oprimidos, condenados da terra, aumentaram ainda mais, são os refugiados da terra, sem hospitalidade em nossa casa comum.

\section{REFERÊNCIAS}

BARBU, Zevedei. Psicología de la democracia y de la dictadura. Buenos Aires: Paidós, 1962. (Traduzido do original em inglês por Noemí Rosenblat).

BAUMAN, Zygmunt. Estranhos à nossa porta. Rio de Janeiro: Zahar, 2017 (Traduzido por Carlos Alberto Medeiros).

BORGES, Valdir; ALCANTARA, Luiz Alberto de. Direitos humanos, educação e ética na era da globalização a partir de Paulo Freire. Revista Espacios. Vol. 39 (n 10) ano 2018. Pag. 12. Disponível em: http://www.revistaespacios.com/a18v39n10/18391012.html

BORGES, Valdir. A reconstrução de uma ética pedagógica libertadora à luz de Paulo

Freire. Curitiba: CRV, 2013.

. Resenha Pedagogia do Oprimido. Revista HISTEDBR On-line, Campinas, n.31, p.211-213, Set.2008. Disponível em:

http://www.histedbr.fe.unicamp.br/revista/edicoes/31/res03 31.pdf

CORTINA ORTS, Adela. Aporofobia, el rechazo al pobre: un desafío para la democracia. Barcelona - España: Paidós, 2017.

FANON, Frantz. Os condenados da terra. Rio de Janeiro: Civilização Brasileira, 1968. (Traduzido por José Laurênio de Melo, prefaciado por Jean-Paul Sartre.

FREIRE. Paulo. Uma educação para a liberdade. 3.ed. Porto: textos marginais, 1974.

Pedagogia do Oprimido. 42. Ed. Rio de Janeiro: Paz e Terra, 2005.

HERMANN, Nadja. A questão do outro e o diálogo. Revista Brasileira de Educação, v. 19, n. 5, p. 477-493, abr./jun. 2014.

NEVES, Maria do Céu Patrão. Ética: dos fundamentos às práticas. Coord. Edições Almedina. 1.ed. Lisboa. 2017.

MEMMI, Albert. Retrato do colonizado precedido pelo retrato do colonizador. Rio de Janeiro: Paz e Terra, 1967. (Traduzido por Roland Corbisier e Mariza Pinto Coelho). 
Revista

Debates Insubmissos

Submetido em: 19/12/2018

Aprovado em: 06/02/2019 